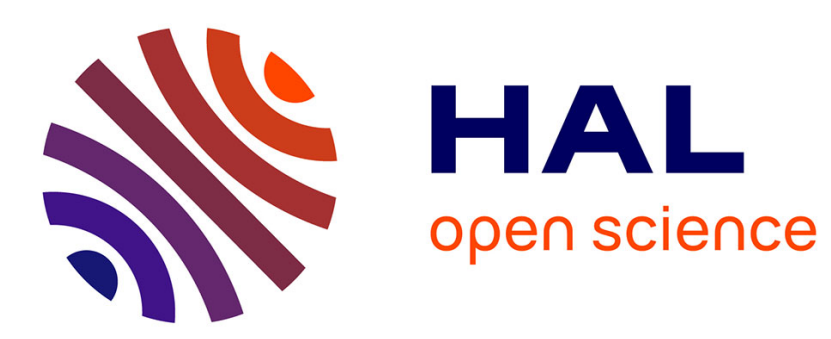

\title{
The Role of Heterosexual Identity Threat in Differential Support for Same-Sex 'Civil Unions' versus 'Marriages'
}

\author{
Michael T. Schmitt, Justin J. Lehmiller, Allison L. Walsh
}

\section{To cite this version:}

Michael T. Schmitt, Justin J. Lehmiller, Allison L. Walsh. The Role of Heterosexual Identity Threat in Differential Support for Same-Sex 'Civil Unions' versus 'Marriages'. Group Processes and Intergroup Relations, 2007, 10 (4), pp.443-455. 10.1177/1368430207081534 . hal-00571661

\section{HAL Id: hal-00571661 \\ https://hal.science/hal-00571661}

Submitted on 1 Mar 2011

HAL is a multi-disciplinary open access archive for the deposit and dissemination of scientific research documents, whether they are published or not. The documents may come from teaching and research institutions in France or abroad, or from public or private research centers.
L'archive ouverte pluridisciplinaire HAL, est destinée au dépôt et à la diffusion de documents scientifiques de niveau recherche, publiés ou non, émanant des établissements d'enseignement et de recherche français ou étrangers, des laboratoires publics ou privés. 


\title{
The Role of Heterosexual
} Identity Threat in Differential Support for Same-Sex 'Civil Unions' versus 'Marriages'

\author{
Michael T. Schmitt \\ Simon Fraser University \\ Justin J. Lehmiller \\ Purdue University
}

\author{
Allison L. Walsh \\ Purdue University
}

\begin{abstract}
Although US citizens generally oppose the legal recognition of same-sex marriages more than civil unions, the reasons for this opposition remain unclear. In two experiments, we presented participants with one of two hypothetical state laws legally recognizing same-sex partnerships. The laws differed only in the label applied to those partnerships (i.e. civil union or marriage). Across both studies, participants expressed less support for same-sex marriages relative to civil unions. In addition, participants considering the marriage law found it more threatening to heterosexuals' rights and social status than did those reading the civil union law, and this threat partially mediated the effect of the relationship label on support for the law. Thus, consistent with social identity theory, opposition to the same-sex marriage label is, in part, due to perceived threats to heterosexual identity.
\end{abstract}

KEYWORDS civil union, gay and lesbian, identity threat, same-sex marriage, social identity

...the dissimilitude between the terms 'civil marriage' and 'civil union' is not innocuous; it is a considered choice of language that reflects a demonstrable assigning of same-sex, largely homosexual, couples to second-class status. Goodridge v. Dept. of Public Health, 798 N.E.2d 941 (Mass. 2003)

IN RECENT years, same-sex couples have taken great strides toward achieving social equality. Since 2001, same-sex couples have obtained full marriage rights in five countries-The Netherlands, Belgium, Canada, Spain, and
South Africa. In all of these countries, marriage is defined legally in gender-neutral termssame-sex marriages and different-sex marriages are both considered simply as 'marriages' with no

\footnotetext{
$\overline{\text { Author's note }}$

Address correspondence to Michael T.

Schmitt, Simon Fraser University,

Department of Psychology, 8888 University

Drive, Burnaby BC, Canada, V5A 1S6

[email: mschmitt@sfu.ca]
} 
differentiation. Starting with Denmark in 1989, 20 countries have adopted legally recognized same-sex 'civil unions' or 'domestic partnerships'. In some countries the rights granted in these partnerships are virtually identical to marriage, but in many cases they offer only a portion of rights typically afforded to married couples. Regardless of the degree to which they fall short of equality for same- and different-sex couples, these partnerships are legally separate from marriage and go by a different name.

Legally sanctioned same-sex partnerships remain a controversial issue. In the US, many efforts to extend the rights of same-sex partners have met with fierce resistance from the political elite. In this article we consider one important aspect of the same-sex relationship debate: how does the label applied to same-sex partnerships affect support for their legality? That is, does support for these relationships depend on whether they are referred to as 'civil unions' or 'marriages'?

Public opinion data find that US citizens are more supportive of civil unions than same sexmarriages (Cauchon, 2004). However, such research typically confounds the relationship label with the amount of rights granted to the partners involved. Thus, we do not know the extent to which the relationship label itself, independent of the rights granted to samesex couples, affects support for recognition of same-sex partnerships. Indeed, we suggest that attending to the symbolic implications of the relationship label, not only the expansion of rights, is critical to understanding support for the recognition of same-sex relationships. Following a social identity approach (Tajfel \& Turner, 1986), we suggest that the degree to which a relationship label is perceived as threatening to the collective identity of heterosexuals should affect support for its legality.

\section{Support for same-sex civil unions and marriages in the US}

In the US, recent public opinion polls indicate greater support for same-sex civil unions than marriages (Brewer \& Wilcox, 2005). For instance, results of a national 2004 Gallup poll suggest weak support for same-sex marriages $(33 \%)$, but relatively stronger support for civil unions (54\%; Cauchon, 2004). Similarly, a number of politicians have expressed a preference for civil unions by supporting legislation that would prohibit same-sex marriages, but would not necessarily preclude the possibility of recognizing these relationships under another name (e.g. 2004 Presidential candidate John Kerry; Farhi, 2004). For example, when asked about legal recognition of same-sex partnerships, Connecticut Governor Jodi Rell said, 'I don't have any trouble with the concept ... If we can address those concerns without marriage, then I am open to the concept' (emphasis added; Yardley, 2005).

Although it seems clear that 'civil unions' currently receive greater support than 'marriages' in the US, research has yet to examine the psychological underpinnings of this preference. Certainly, opposition may stem from people perceiving (with some accuracy) that the recognition of gender-neutral marriages grants more legal rights and protection to gay, lesbian, bisexual, or transgender people than the recognition of civil unions, as civil unions typically provide only a subset of the benefits that different-sex marriages provide. In the United States, Maine, Hawaii, the District of Columbia, and Washington have created legal unions for same-sex couples that offer only a subset of the rights of marriage. Therefore, the relative opposition to same-sex marriage may partially reflect a heterosexist opposition to the greater rights it could provide to same-sex partnerships.

Public opinion research does not rule out this explanation, as this research does not control for inferences about the strength of the law based on the relationship label. Thus, existing data does not offer much evidence as to the effect of the relationship label independent of inferences about the rights granted to same-sex couples. In the present study we consider the intriguing possibility that the relative lack of support for marriage might also be due to its symbolic implications, independent of its increased legal protections. Interestingly, Connecticut, Vermont, 
New Jersey, and California have created legal same-sex unions that are explicitly defined as providing equal access to all the rights and responsibilities of marriage, but have chosen to label these 'unions' as something other than marriage. In the US, only Massachusetts recognizes gender-neutral marriage.

We adopt a social identity approach (Tajfel \& Turner, 1986) to addressing this issue and posit that the marriage label threatens the identities of heterosexuals more than the civil union label. That is, we suggest that weaker support for samesex marriage laws, relative to civil unions laws, is partially due to increased perceptions of a threat to the heterosexual ingroup posed by the marriage label, and the motivation to protect that group identity.

\section{Social identity and same-sex relationships}

According to social identity theory (SIT; Tajfel \& Turner, 1986) people's social category memberships constitute important aspects of selfdefinition. Further, SIT assumes that people are motivated to perceive valued ingroups as positively distinct from relevant outgroups. One of SIT's central contributions is the notion that ingroup status is not a function of the absolute prestige, resources, or power enjoyed by the high status group, but is a relative judgment based on comparisons between the ingroup and other groups that are salient or relevant in context. In other words, the status of outgroups has implications for the ingroup identity. Thus, individuals who perceive an outgroup threat to the positive distinctiveness of a valued ingroup identity will take advantage of opportunities to protect their ingroup's distinctiveness (for a review see Jetten, Spears, \& Postmes, 2004). For members of high status groups who perceive their higher status as legitimate, attempts by lower status groups to improve their status are likely to be met with social competition, or deliberate attempts to maintain the status boundaries between groups (Abrams, Carter, \& Hogg, 1989; Branscombe, Ellemers, Spears, \& Doosje, 1999; Turner \& Brown, 1978).
Following this line of reasoning, heterosexual people are likely to experience the legal recognition of same-sex partnerships as a threat to their social identity. This threat should arise because legally sanctioned same-sex relationships serve to decrease the status difference between heterosexuals and homosexuals, as homosexuals stand to gain rights that they did not previously have. Thus, despite having no implications for the rights granted to heterosexual couples in an absolute sense, extending rights to same-sex couples threatens the relative status advantage enjoyed by heterosexuals. Overall, heterosexuals appear to feel entitled to their higher status position, expressing relatively negative attitudes toward homosexuals (e.g. Kite \& Whitley, 1996) and stigmatizing them as abnormal or immoral (e.g. Pew Research Center, 2003). Thus, when same-sex relationships are offered the same legal recognition that different-sex relationships currently receive, heterosexual people are likely to resist this threat to their privileged identity.

By threatening the relatively advantaged status of heterosexuals, both same-sex marriages and civil unions represent a threat to heterosexual group identity (even though they have no effect on the 'absolute' status of heterosexual people). However, we propose that same-sex marriages represent a greater threat to the positive distinctiveness of heterosexual identity, even if only on a symbolic level. By describing both same-sex and different-sex partnerships with the same term, the marriage label implies that the different types of relationships are similar and undermines the distinctiveness of the heterosexual group identity. In contrast, even if identical rights are granted to same-sex couples through civil union legislation, heterosexual people can maintain some sense of positive distinctiveness by creating a separate label for same-sex relationships, and keeping the more traditional and valued term for themselves. Thus, assuming that heterosexual people are invested in their heterosexual group identity, they are more likely to support a law recognizing same-sex civil unions over a law recognizing same-sex marriages because the marriage label represents a greater threat to heterosexual identity. 


\section{The present research}

The goal of the present research was to examine whether, all else equal, the label applied to samesex relationships affects support for their legality. Thus, in two experiments we presented participants with one of two different versions of a hypothetical state law that would legally acknowledge same-sex relationships and provide same-sex couples with the same rights and protections that different-sex couples currently receive. The only thing that differed between the two laws was the label applied: 'marriage' versus 'civil union'. We then measured participants' support for the law, as well their beliefs about various forms of threat that same-sex relationships may pose.

Although our primary interest was in heterosexual threat (in line with SIT), we also examined other forms of threat that could serve as plausible alternative mediators, such as threats to the institution of marriage, threats to the functioning of society, and threats to 'the family'. We examined these other forms of threat because they are reasons people commonly cite for not supporting gay marriage (e.g. Pew Research Center, 2003), and are clearly evident in public discourse on the issue of same-sex marriage. For instance, in a 2004 radio address by President George W. Bush, he states that, 'If courts create their own arbitrary definition of marriage ... the institution is weakened'. Moreover, he refers to marriage as 'the basis of an orderly society' and states that 'changing the definition of traditional marriage will undermine the family structure' (Longley, 2004). The implication of these comments is that same-sex marriage threatens society, families, and the institution of marriage itself. A similar case for these forms of threat could be drawn from current social psychological theorizing on values and prejudice. That is, several studies have demonstrated that a belief that gays and lesbians violate family values is associated with anti-gay prejudice (e.g. Haddock \& Zanna, 1998; Vescio \& Biernat, 2003). Thus, such studies would seem to suggest that a threat to values, particularly family values, would affect support for recognition of same-sex relationships.

\section{Hypotheses}

We predicted an effect of the relationship label such that same-sex civil unions would receive stronger support than same-sex marriages (Hypothesis 1). Additionally, we predicted that the same-sex marriage law would be perceived as more threatening to heterosexuals than the civil union law (Hy-pothesis 2). Lastly, we predicted that perceptions of heterosexual threat would mediate the association between relationship label and support for the law (Hypothesis 3).

We did not advance specific hypotheses regarding the other types of threat assessed (i.e. threat to society, family values, and the institution of marriage), but included them for two reasons. First, these threats are representative of the content of public discourse opposing same-sex marriage. Second, these forms of threat could serve as potential alternative mediators of the hypothesized effect of the label on support for the law.

\section{Experiment 1}

We conducted Experiment 1 as a general test of the above hypotheses. When examining the effect of experimental condition, we controlled for participants' levels of anti-gay prejudice. Participants with negative attitudes toward gay and lesbian people are likely to be more opposed to both civil unions and same-sex marriages than less prejudiced participants because both types of partnerships expand the rights of people in homosexual relationships. Because our goal was to examine the differential support for civil unions and marriages due to the label used, rather than the expansion of rights, we chose to partial out a source of variance common to both types of relationships. Additionally, controlling for variance in anti-gay prejudice, a variable we assumed would affect support for both types of partnerships, increases statistical power to detect the effects of a rather subtle manipulation (Frigon \& Laurencelle, 1993).

\section{Method}

Participants Participants were heterosexual psychology students at a university in Indiana 
( $N=115 ; 67$ males, 48 females) who chose to participate in this study for credit in a general psychology course. Students signed up for participation through an internet site where this study was listed among many others. The sample was predominately European American $(86.1 \%)$, with few participants indicating that they were African American (2.6\%), Asian American (7.0\%), or Hispanic American (2.6\%). On average, participants were 19 years old $(S D=1.30)$.

Materials and procedure Working independently, participants completed the study in small groups. After receiving informed consent, we presented participants with a hypothetical Indiana state law that would allow for legal recognition of same-sex relationships and provide same-sex partners with all of the same rights and protections that different-sex married partners currently receive. Participants received one of two different versions of the law (see appendix). The two laws differed only in the specific label applied to the relationship: 'civil union' versus 'marriage'. The rest of the information was virtually identical (the only exception being that the couple members were referred to as 'spouses' under the marriage law and 'partners' under the civil union law) and informed participants of various rights and benefits that would be afforded to same-sex couples under the new law.

In reality, the Indiana state legislature has been far less accepting of same-sex relationships than the laws read by participants. In 1997, Indiana legislators passed a law banning gay marriage (Indiana Code 31-11-1-1). In 2005, Indiana legislators passed an amendment to the state's Constitution barring same-sex couples from marriage and similar legal structures such as civil unions. To become law, the amendment would have to be approved again in the 2007-2008 legislative session and then by Indiana voters. Across the US, 26 states have passed constitutional amendments banning same-sex marriage, and 43 have laws that define marriage as 'between a man and a woman'.

Although the two experimental conditions specified laws that were identical in the rights they granted, it is still possible that participants would infer that the marriage law had greater consequences for the rights of same-sex couples than the civil union law. To ensure that any effects of the manipulation were due to the label itself and not differential perceptions of the amount of rights granted, we included a measure of the extent to which the laws were perceived as granting equal rights to same-sex partners. After reading about the law, participants responded to the question 'How much will this law expand the rights of homosexuals?' on a scale ranging from 'will not expand homosexual rights at all' (1) to 'will expand homosexual rights greatly' (7).

Participants then completed the dependent measures in the order described below. Unless otherwise noted, participants responded to questionnaire items using a 7-point scale. For most scales, the endpoints ranged from strongly disagree (1) to strongly agree (7). However, where appropriate, the endpoints differed to reflect the content of the statement (e.g. very negative to very positive). Overall scores for the measures were obtained by reverse-scoring where appropriate and averaging the individual item scores. After completing all questionnaires, participants were fully debriefed.

Support for the law Participants rated their support for the law by indicating their agreement or disagreement with the following statements: 'I am in support of this law', 'I would be willing to vote for legislators who supported this law', and 'Overall, how do you feel about this law?' $(\alpha=.97)$.

Perceived threat Participants rated the extent to which the laws present a threat to society ('This law would create societal problems', 'This law would be good for society', and 'This law threatens the very fabric of society'; $\alpha=.86$ ), heterosexuals ('This law threatens heterosexual rights', 'Does this law threaten the rights of heterosexuals?', and 'Does this law protect or threaten civil rights?'; $\alpha=.83$ ), family values ('This law is harmful to families and children', 'This law is inconsistent with family values', and 'Does this law protect children or harm children?'; $\alpha=.89$ ), and the institution of marriage ('I think this law would 
change the definition of marriage in a negative way', 'I think this law would positively affect the institution of marriage', and 'Does this law harm or strengthen the institution of marriage?'; $\alpha=.92$ ). We also included items assessing threat to participants' personal relationships ('I think this law might negatively affect any marriage I might have now or in the future', 'This law would be a good thing for romantic relationships I might have', and 'This law would do no harm to me personally'; $\alpha=.56$ ). A principal components factor analysis of all of the threat items yielded a two-factor solution explaining $68 \%$ of the total item variance. All of the items assessing threats to society, family values, and the institution of marriage as well as one of the personal threat items loaded on a single factor (all factor loadings $>.50$ ). In contrast, the heterosexual threat items and two of the personal threat items loaded on the other factor (all factor loadings $>.60$ ). The only item to load on more than one factor at a level greater than .40 was one of the personal threat items. Because the personal threat items did not load consistently on one of the factors, it is difficult to determine their meaning. For that reason, and because these personal threat items do not clearly map onto threats to heterosexuals as a group, we dropped these three items from the primary analyses.

Anti-gay prejudice Anti-gay prejudice was assessed with Herek's (1988) Attitudes Toward Lesbians and Gay Men Scale $(\alpha=.96)$. Sample items from this measure include 'I think male homosexuals are disgusting' and 'Lesbians are sick'.

Demographic items Participants also completed a standard demographic questionnaire that included items assessing sexual orientation, gender, age, and ethnicity. The few participants who did not indicate that they were heterosexual were not included in the analyses.

\section{Results and discussion}

Preliminary analyses We first wanted to rule out the possibility that participants inferred that the marriage law and civil union law differentially extended the rights of same-sex couples.
Importantly, responses to the question about the amount of rights granted were not related to experimental condition $(F(1,113)=1.28$, $p=.261)$. Participants perceived both the marriage law $(M=6.29, S D=1.08)$ and the civil union law $(M=6.02, S D=1.51)$ as greatly expanding the rights of same-sex couples. Therefore, we can be reasonably confident that any effects due to the manipulation were a result of the relationship labels and not inferences about the amount of rights granted by the laws.

In the analyses that follow, we controlled for participants' levels of anti-gay prejudice. However, in order to satisfy the assumptions of the analysis of covariance approach, the relationship between the covariate and dependent variables must be independent of condition (Frigon \& Laurencelle, 1993). Importantly, anti-gay prejudice did not differ significantly across conditions $(F(1,113)=0.17, p=.681)$, nor did it significantly interact with experimental condition to predict support for the law or any of the measured forms of threat. Given the lack of interactions, anti-gay prejudice appears to be accounting for variance in support for recognizing samesex relationships per se, regardless of the label applied to those relationships.

Effects of label on support for the law Consistent with Hypothesis 1, participants differed in their favorability toward the two laws $(F(1,112)=7.91$, $p=.006)$ (Eta-squared $=.07)$. Specifically, participants showed significantly less support for the marriage law $(M=3.62, S E=0.18)$ than the civil union law $(M=4.33, S E=0.18)$. Anti-gay prejudice was negatively associated with support for the law $(p<.001)$ (Eta-squared $=.63)$.

Perceptions of threat We next examined whether the label affected participants' perceptions of threat. Consistent with Hypothesis 2, perceptions of heterosexual threat marginally differed across experimental conditions $(F(1,112)=3.50, p=.064)($ Eta-squared $=.03)$. As shown in Table 1, heterosexual threat tended to be higher in the gay marriage condition $(M=3.01, S E=0.15)$ than the civil union condition $(M=2.61, S E=0.15)$. However, the other types of threat assessed were not affected by 
Table 1. Experiment 1: Support for the law and threats by experimental condition

\begin{tabular}{lcr}
\hline Variable & Same-sex marriage law & Civil union law \\
$n=58$ & 57 \\
\hline Support for the law & $3.62_{\mathrm{a}}(0.18)$ & $4.33_{\mathrm{b}}(0.18)$ \\
Threat to heterosexuals & $3.01_{\mathrm{a}}(0.15)$ & $2.61_{\mathrm{b}}(0.15)$ \\
Threat to society & $4.56_{\mathrm{a}}(0.14)$ & $4.26_{\mathrm{a}}(0.14)$ \\
Threat to family values & $4.27_{\mathrm{a}}(0.15)$ & $4.17_{\mathrm{a}}(0.16)$ \\
Threat to marriage & $4.57_{\mathrm{a}}(0.16)$ & $4.36_{\mathrm{a}}(0.16)$ \\
Threat composite & $4.47_{\mathrm{a}}(0.12)$ & $4.26_{\mathrm{a}}(0.13)$ \\
$\quad$ & &
\end{tabular}

Notes: Differing subscripts indicate within-row significant differences $(p<.05$ or less), except for threat to heterosexuals, where differing subscripts indicate within-row marginally significant differences $(p<.07)$. Values in parentheses are standard errors. All values are controlling for anti-gay prejudice. The scales for all measures ranged from 1 (strongly disagree/very negative) to 7 (strongly agree/very positive).

the experimental manipulation. Thus, threats to society $(F(1,112)=2.35, p=.128)$, family values $(F(1,112)=0.25, p=.618)$, and the institution of marriage did not differ by condition $(F(1,112)=0.91, p=.342)$, nor did a composite measure consisting of all three of these forms of threat $(F(1,112)=1.37, p=.244)$. In all of the above analyses, anti-gay prejudice was a significant covariate, being positively related to perceptions of threat $(p<.001)$.

Mediational analyses We next examined whether perceptions of threat mediated the effect of the relationship label on support for the law, using procedures outlined by Baron and Kenny (1986). The first and second criteria required to demonstrate mediation are effects of the independent variable on both the dependent variable and the mediator. Both of these criteria were met for heterosexual threat. Specifically, experimental condition significantly predicted support for the law (the dependent variable; $\mathrm{B}=-.70 ; t(112)=-2.81, p=.006)$ and marginally predicted heterosexual threat (the hypothesized mediator; $\mathrm{B}=.40 ; t(112)=1.87, p=.064)$.

To meet the third criterion, the mediator must predict the dependent variable controlling for the effects of the independent variable. When we examined the effect of heterosexual threat on support for the law when relationship label was simultaneously taken into account, heterosexual threat was indeed a significant predictor of support for the law $(\mathrm{B}=-.38 ; t(111)=-3.58$; $p<.001)$, such that higher levels of threat were associated with less support. Finally, meeting the fourth criterion, the effect of relationship label on support for the law was reduced when controlling for heterosexual threat $(\mathrm{B}=-.55$; $t(111)=-2.28, p=.024)$. Results of a Sobel test corroborated these findings by indicating that the mediated effect was marginally significant $(z=-1.66, p=.097){ }^{1}$

In sum, the results of Experiment 1 were supportive of our hypotheses. First, consistent with public opinion research, participants preferred the civil union law to the marriage law. Second, in line with predictions based on social identity theory, heterosexual threat partially mediated this effect. However, the statistical test for mediation was only marginally significant. Thus, in an attempt to provide more definitive support for our hypotheses, we refined our research materials and conducted a second study.

\section{Experiment 2}

The primary limitation of Experiment 1 was that the items used to measure heterosexual threat were narrowly limited to perceptions of threats to heterosexuals' rights and did not directly ask about heterosexual identity per se. Therefore, in Experiment 2 we measured the threat to heterosexual group identity more directly, specifically in terms of the status and identity of heterosexuals as a group. Aside from this important change to the measurement of our hypothesized mediator, 
the design and materials were similar to those used in Experiment 1.

\section{Method}

Participants Heterosexual undergraduates at a university in Indiana $(N=218 ; 112$ males, 106 females) participated for credit in a general psychology course. The sample was predominately European American (84.4\%), with few participants indicating that they were African American (6.4\%), Asian American (5.5\%), Hispanic American (1.8\%), or 'Other' (1.8\%). On average, participants were 19.58 years old $(S D=1.42)$.

Materials and procedure After receiving informed consent, we presented participants with a manipulation that was identical to that used in Experiment 1 (see appendix). Thus, participants read either the same-sex marriage law or the same-sex civil union law. Again, to ensure that any effects of the manipulation were due to the label itself and not to differential perceptions of the amount of rights granted, participants were asked 'How much will this law expand the rights of homosexuals?' on a scale ranging from 'will not expand homosexual rights at all' (1) to 'will expand homosexual rights greatly' (7).

Participants then completed the dependent measures in the order described below. As in Experiment 1, participants responded to all questionnaire items using a 7-point scale. After completing all questionnaires, participants were fully debriefed.

Support for the law Participants completed the same three-item measure of support for the law used in Experiment $1(\alpha=.99)$.

Perceived threat Relying on the same items used in Experiment 1, participants rated the extent to which the laws present a threat to society (3 items; $\alpha=.87$ ), family values (3 items; $\alpha=.87$ ), and the institution of marriage (3 items; $\alpha=.92$ ). Participants also completed a new measure of the extent to which the laws threaten heterosexuals that focused more on threats to the social status of heterosexuals than heterosexuals' rights
('This law harms the social status of heterosexuals', 'This law strips heterosexuals of their rightful place in society', 'This law threatens heterosexuals', 'This law is harmful to heterosexuals'; $\alpha=.93$ ). Lastly, because the meaning of the personal threat items administered in Experiment 1 was unclear, they were not included in the second study. A principal components factor analysis of all of the threat items yielded a two-factor solution explaining $77 \%$ of the total item variance. All of the items assessing threats to society, family values, and the institution of marriage loaded on one factor (all factor loadings $>.60$ ), while only the heterosexual threat items loaded on the other factor (all factor loadings $>.80$ ). No items loaded on more than one factor at a level greater than 40 .

Other measures Anti-gay prejudice was assessed with Herek's (1988) Attitudes Toward Lesbians and Gay Men Scale $(\alpha=.97)$. Additionally, participants completed the same demographic items administered in Experiment 1.

\section{Results and discussion}

Preliminary analyses Responses to the question about the amount of rights granted were not related to the experimental condition $(F(1,216)=$ $1.10, p=.295)$. As in Experiment 1, participants perceived both the marriage law $(M=6.39$, $S D=1.00)$ and the civil union law $(M=6.25$, $S D=0.99)$ as greatly expanding the rights of same-sex couples. Therefore, any effects due to the manipulation are likely to be a result of the relationship labels themselves and not inferences about the amount of rights granted by the laws.

In the analyses that follow, we controlled for anti-gay prejudice. Anti-gay prejudice was not related to the experimental condition $(F(1,216)=$ $0.03, p=.869)$. Additionally, as in Experiment 1 , anti-gay prejudice did not interact with the experimental condition to predict support for the law or any of the relevant forms of threat assessed. ${ }^{2}$

Effects of label on support for the law Consistent with predictions, participants differed in their favorability toward the two laws $(F(1,215)=7.99$, $p=.005)($ Eta-squared $=.04)$. Participants were 
significantly less supportive of the marriage law $(M=4.03, S E=0.09)$ than the civil union law $(M=4.41, S E=0.09)$. Anti-gay prejudice was a significant covariate and was negatively associated with support for the law $(p<.001)$ $($ Eta-squared $=.79)$.

Perceptions of threat In line with our predictions, perceptions of heterosexual threat differed across experimental conditions $(F(1,215)=6.62$, $p=.011)($ Eta-squared $=.03)$. As shown in Table 2, heterosexual threat was higher in the marriage condition $(M=2.86, S E=0.10)$ compared to the civil union condition $(M=2.49$, $S E=0.10)$. In contrast, threats to society $(F(1,215)=1.17, p=.280)$, and family values $(F(1,215)=2.19, p=.140)$, did not differ by condition. However, threat to the institution of marriage $(F(1,215)=3.58, p=.060)$, and a composite measure consisting of the three alternate forms of threat were marginally greater in the marriage condition relative to the civil union condition $(F(1,215)=3.11, p=.079)$. As a covariate, anti-gay prejudice was positively related to all of the measures of threat $(p<.001)$.

Mediational analyses Next, we examined whether perceptions of threat mediated the impact of relationship label on support for the law. First, experimental condition significantly predicted both support for the law (the dependent variable; $\mathrm{B}=-.38, t(215)=-2.83, p=.005)$ and heterosexual threat (the hypothesized mediator; $\mathrm{B}=.37, t(215)=2.57, p=.011)$.
Second, when we examined the effect of the relationship label on support for the law when heterosexual threat was simultaneously taken into account, heterosexual threat significantly predicted support for the law $(\mathrm{B}=-.36 ; t(214)=$ $-6.21, p<.001)$, such that higher levels of threat were associated with less support. Finally, when controlling for heterosexual threat, the effect of the relationship label on support for the law was reduced $(\mathrm{B}=-.24 ; t(214)=-1.94, p=.053)$. Results of a Sobel test corroborated these findings by indicating that the mediation was significant $(z=2.38, p=.018)$. Thus, heterosexual threat was at least partially responsible for participants' reduced support for the same-sex marriage law relative to the civil union law.

Next, because some of the other forms of threat assessed differed marginally across conditions, we also examined the possibility that these threat measures could serve as alternative mediators of the observed effect. However, results of Sobel tests were only marginally significant for both threat to the institution of marriage $(z=1.84$, $p=.066)$ and the composite threat measure $(z=1.75, p=.081)$. Thus, the evidence obtained for heterosexual threat as the mediator appears to be more conclusive than that obtained for these other forms of threat. ${ }^{3}$

\section{General discussion}

We employed a novel approach to addressing the issue of why same-sex civil unions are preferred over same-sex marriages. That is,

Table 2. Experiment 2: Support for the law and threats by experimental condition

\begin{tabular}{lcr}
\hline Variable & Same-sex marriage law & Civil union law \\
& $n=110$ & $n=108$ \\
\hline Support for the law & $4.03_{\mathrm{a}}(0.09)$ & $4.41_{\mathrm{b}}(0.10)$ \\
Threat to heterosexuals & $2.86_{\mathrm{a}}(0.10)$ & $2.49_{\mathrm{b}}(0.10)$ \\
Threat to society & $3.95_{\mathrm{a}}(0.09)$ & $3.82_{\mathrm{a}}(0.09)$ \\
Threat to family values & $3.78_{\mathrm{a}}(0.10)$ & $3.56_{\mathrm{a}}(0.10)$ \\
Threat to marriage & $4.52_{\mathrm{a}}(0.11)$ & $4.24_{\mathrm{a}}(0.11)$ \\
Threat composite & $4.05_{\mathrm{a}}(0.08)$ & $3.86_{\mathrm{a}}(0.08)$ \\
$\quad$ & & \\
\hline
\end{tabular}

Notes: Differing subscripts indicate within-row significant differences $(p<.05$ or less). Values in parentheses are standard errors. All values are controlling for anti-gay prejudice. The scales for all measures ranged from 1 (strongly disagree/very negative) to 7 (strongly agree/very positive). 
rather than relying exclusively on survey results and correlational data, we conducted two experiments testing a social identity theory explanation for differential support for civil unions and marriages. Overall, our hypotheses were supported. In both studies, support for same-sex civil unions was higher than support for samesex marriages, mirroring effects found in recent public opinion polls (Brewer \& Wilcox, 2005). This finding is particularly important because we obtained it even when controlling for the amount of rights granted by the laws. Thus, this is the first evidence of which we are aware indicating that the relationship label itself affects support for same-sex relationship legislation, independent of the amount of rights granted to same-sex partners.

Importantly, we also found that participants presented with the marriage law perceived more threat to heterosexuals than participants presented with the civil union law. Further, our results in both studies indicate that heterosexual threat partially mediated the effect of the relationship label on support for the law. None of the other forms of threat assessed could mediate this association.

These findings offer support for one of SIT's (Tajfel \& Turner, 1986) core contributions-the contention that people are motivated to achieve a positive social identity vis-a-vis relevant outgroups. In terms of absolute rights and privileges, the marriage law would not harm heterosexual people. Nonetheless, our participants found the marriage law more threatening to heterosexuals than the civil union law, because, as SIT would suggest, ingroup identity results from intergroup comparisons. Compared to the civil union law, the marriage law is more threatening to the positive distinctiveness of the heterosexual group identity by elevating same-sex relationships to the same level as different-sex ones. Other theoretical perspectives assume that threat (Duckitt, 2006) and symbolic aspects of intergroup relationships (Kinder \& Sears, 1981) are important predictors of discrimination and intergroup attitudes. However, SIT is unique (except where incorporated into other perspectives, e.g. Stephan \& Stephan, 2000) in its assumptions that ingroup identity results from and is constructed through intergroup comparisons, and that intergroup discrimination results not just from attitudes toward the outgroup (prejudice) but also from the motivation to protect ingroup identity.

Our results suggest that the US public may be relatively more supportive of same-sex civil unions in part because they are less threatening to heterosexual identity than same-sex marriages. This contention is bolstered by the finding that none of the other types of threat assessed in this study mediated the association between relationship label and support for the law. SIT may therefore prove to be a useful framework for understanding people's support for or opposition to recognizing same-sex relationships. Indeed, our results suggest that identity concerns do play a role in understanding differential support for marriage and civil union laws.

\section{Limitations and future directions}

There are multiple strengths of the present study. For instance, this is the first study to show that the relationship label itself can affect support for granting equal rights to same-sex couples. Even when controlling for the amount of rights granted to same-sex couples, we found that the marriage label elicited less support than the civil union label. However, it is important to note that in the 'real world', the rights attached to these two labels typically are not equivalent. Thus, although they cannot account for the effects observed in our studies, perceptions of the amount of rights granted could indeed explain some of the differential support for marriages compared to civil unions.

Second, this study provides one of the first experimental investigations into the issue of why same-sex civil unions are preferred over samesex marriages. Testing predictions derived from SIT, we found evidence for a novel and nonobvious explanation for the label effect- that the marriage label threatens heterosexual identity despite posing no threat to heterosexual people in absolute terms. Confidence in our theoretical explanation is bolstered by lack of support for plausible alternative mediators, as none of the other forms of threat were significantly affected by the label. Finally, this research addresses an 
important and controversial issue that is at the center of ongoing political debate.

However, there are also a few limitations to this work. First, our samples only included undergraduate college students at a Midwestern university. Thus, the extent to which these findings might generalize to more diverse samples is a question for future research. Along the same lines, our results cannot speak to the views of gays and lesbians on their preference for different labels, which may be an interesting avenue for further inquiry. Indeed, some gay men, lesbians, and bisexuals may object to legalized same-sex partnerships, particularly same-sex marriages, to the extent that they view the institution of marriage itself as being fundamentally heterosexist (Lannutti, 2005).

Although we did find some support for our hypothesized mediation, heterosexual threat did not appear to fully mediate the association between relationship label and support for the law. Of course, tests for mediation are fairly conservative, and mediated relationships may not be reliable for a variety of reasons (Haslam \& McGarty, 1998, p. 259). However, given that we did not obtain convincing evidence for mediation by other forms of threat, heterosexual threat appears to be the most promising explanation for differences in support for same-sex marriages versus civil unions. An important direction for future research, then, is to expand upon the measurement of heterosexual threat to further examine its potential role in affecting support for same-sex relationship legislation.

Finally, it is clear that the label applied to legally recognized same-sex relationships is only one factor affecting support. In our data, antigay prejudice accounted for a large portion of the variance in support for both same-sex marriage and civil union laws. Importantly, though, the effect of the label was independent of antigay prejudice. In other words, the differential support for marriages and civil unions was not isolated or even exaggerated among the more prejudiced participants. This suggests, perhaps, that the bias against the marriage label involves subtler forms of prejudice that are not tapped by the measure of blatant anti-gay prejudice we used.
Indeed, our results suggest that in addition to studying the consequences of negative attitudes toward gay men and lesbians, researchers should also attend to the attitudes toward and perceptions of heterosexual identity.

In conclusion, the results of these two experiments contribute to our understanding of why heterosexual people tend to favor same-sex civil unions over marriages. Consistent with predictions derived from social identity theory, our results suggest that the marriage label itself is experienced by heterosexuals as threatening to their identity and that this threat may lead to decreased support for same-sex marriage laws. Public opinion polls find lukewarm support for civil unions, suggesting some erosion in the perceived legitimacy of existing inequalities in rights granted to people of different sexual orientations. However, as long as heterosexuals as a group remain motivated to protect their privileged status, it appears that they prefer to address these inequalities by creating separate labels to assert the distinctiveness and superiority of heterosexuality.

\section{Notes}

1. We conducted additional analyses to test for mediation by heterosexual threat while controlling for the other types of threat. In these analyses heterosexual threat still significantly predicted support for the law. Consistent with the main analysis, a Sobel test for mediation by heterosexual threat was marginally significant.

2. Although not a central variable in our analyses, we also assessed religious fundamentalism with Altemeyer and Hunsberger's (1992) scale. We examined whether experimental condition interacted with religious fundamentalism in predicting our dependent measures of interest. As was the case for our measure of anti-gay prejudice, no significant interactions emerged.

3. We conducted additional analyses to test for mediation by heterosexual threat while controlling for the other threats assessed. In analyses controlling for the other threats, heterosexual identity threat remained a significant predictor of support for the law and a Sobel test for mediation by heterosexual threat was significant. 


\section{Acknowledgement}

Study 1 was conducted as part of the third author's Honors Thesis in the Department of Psychological Sciences, Purdue University.

\section{References}

Abrams, D., Carter, J., \& Hogg, M.A. (1989). Perceptions of male homosexuality: An application of social identity theory. Social Behaviour, 4, 253-264.

Altemeyer, B., \& Hunsberger, B. (1992). Authoritarianism, religious fundamentalism, quest, and prejudice. International Journal for the Psychology of Religion, 2, 113-133.

Baron, R. M., \& Kenny, D. A. (1986). The moderator-mediator variable distinction in social psychological research: Conceptual, strategic, and statistical considerations. Journal of Personality and Social Psychology, 51, 1173-1182.

Branscombe, N.R., Ellemers, N., Spears, R., \& Doosje, B. (1999). The context and content of social identity threat. In N. Ellemers, R. Spears, \& B. Doosje (Eds.), Social identity: Context, commitment, content (pp. 35-58). Oxford, UK: Blackwell.

Brewer, P.R., \& Wilcox, C. (2005). Same-sex marriage and civil unions. Public Opinion Quarterly, 69, 599-616.

Cauchon, D. (2004, March). Civil unions gain support. USA Today. Retrieved May 1, 2005, from http://usatoday.com/news/nation/2004-03-09gaymarriage-usat_x.htm.

Duckitt, J. (2006). Differential effects of right wing authoritarianism and social dominance orientation on outgroup attitudes and their mediation by threat from and competitiveness to outgroups. Personality and Social Psychology Bulletin, 32, 684-696.

Farhi, P. (2004, May). Kerry again opposes samesex marriage. Washington Post. Retrieved May 1, 2005, from http://www.washingtonpost.com/ wp-dyn/articles/A28118-2004May14.html.

Frigon, J.Y., \& Laurencelle, L. (1993). Analysis of covariance: a proposed algorithm. Educational and Psychological Measurement, 53, 1-18.

Haslam, S.A., \& McGarty, C. (1998). Research methods and statistics in psychology. London: Sage.

Haddock, G., \& Zanna, M. P. (1998).

Authoritarianism, values, and the structure of antigay attitudes. In G. M. Herek (Ed.), Stigma and sexual orientation:Understanding prejudice against lesbians, gay men, and bisexuals. Psychological perspectives on lesbian and gay issues (Vol. 4, pp. 82-107). Thousand Oaks, CA: Sage. Herek, G.M. (1988). Heterosexuals' attitudes toward lesbians and gay men: Correlates and gender differences. Journal of Sex Research, 25, 451-477.

Jetten, J., Spears, R., \& Postmes, T. (2004). Intergroup distinctiveness and differentiation: A meta-analytic integration. Journal of Personality and Social Psychology, 86, 862-879.

Kinder, D.R., \& Sears, D.O. (1981). Prejudice and politics: Symbolic racism versus racial threats to the good life. Journal of Personality and Social Psychology, 40, 414-431.

Kite, M. E., \& Whitley, B. E. (1996). Sex differences in attitudes toward homosexual persons, behaviors, and civil rights: A meta-analysis. Personality and Social Psychology Bulletin, 22, 336-353.

Lannutti, P.J. (2005). For better or worse: Exploring the meanings of same-sex marriage within the lesbian, gay, bisexual and transgendered community. Journal of Social and Personal Relationships, 22, 5-18.

Longley, R. (2004). Bush backs gay marriage ban amendment; Blames 'activist' judges for changing meaning of marriage. Retrieved July 4, 2005 from http://usgovinfo.about.com/od/ rightsandfreedoms/a/bushvgays.htm.

Pew Research Center. (2003). Religious beliefs underpin opposition to homosexuality; Republicans unified, Democrats split on gay marriage. Retrieved July 3, 2005 from http://people-press.org/ dataarchive/.

Stephan, W.G., \& Stephan, C.W. (2000). An integrated threat theory of prejudice. In S. Oskamp (Ed.), Reducing prejudice and discrimination (pp. 23-45). Mahwah, NJ: Erlbaum.

Tajfel, H., \& Turner, J. C. (1986). The social identity theory of intergroup behavior. In S. Worchel \& L. W. Austin (Eds.), Psychology of intergroup relations (pp. 7-24). Chicago: Nelson-Hall.

Turner, J.C., \& Brown, R. (1978). Social status, cognitive alternatives, and intergroup relations. In H. Tajfel (Ed.), Differentiation between social groups (pp. 201-234). London: Academic Press.

Vescio, T. K., \& Biernat, M. (2003). Family values and antipathy toward gay men. Journal of Applied Social Psychology, 33, 833-847.

Yardley, W. (2005, March 7). In Connecticut, shifting ground on gay civil unions. New York Times, p. B5. 
Paper received 7 December 2005; revised version accepted 21 February 2007.

\section{Biographical notes}

michael t. Schmitt received his $\mathrm{Ph}$.D. from the University of Kansas in 2002. While in graduate school, Michael was awarded a Fulbright Scholarship to study in the Netherlands. Previously an Assistant Professor at Purdue University, Michael is now an Assistant Professor at Simon Fraser University, Burnaby, BC, Canada. His research examines collective identity and responses to social inequality.

JUSTIN J. LEHMILLER is currently a doctoral candidate in social psychology at Purdue University. His research explores the effects of prejudice and discrimination on people's romantic relationships.

ALLISON L. WALSH graduated with a B.A. in Psychology from Purdue University in 2005. This collaborative research effort began with Allison's project for the Purdue Psychology Research Focused Honors Program. Allison is currently a graduate student in social work at Washington University in St. Louis.

\section{Appendix}

\section{Same-sex marriage law (same-sex civil union law)}

Imagine that the state legislature has passed a new law granting legal recognition of same-sex marriages (same-sex civil unions). This samesex marriage law (same-sex civil union law) will provide to couples in same-sex marriages (same-sex civil unions) ALL the rights and benefits provided to couples in heterosexual marriages. Because of the equality provided to same-sex couples, this law is considered very strong. Please carefully read and consider the information below, as you will be asked about it in the following pages.
Below are some of the many rights and benefits provided to same-sex married couples (same-sex civil unions) under this new law:

-Filing joint income tax returns to enjoy tax benefits for married couples (couples).

-Inheriting from a deceased spouse (partner) if he or she lacked a valid will.

- Receiving social security, Medicare and disability benefits for spouses (partners).

- Receiving veteran's and military benefits for spouses (partners), such as those for education, medical care, or special loans.

-Obtaining health insurance and other benefits through a spouse's (partner's) employer.

-Receiving wages, workers' compensation, and retirement benefits for a deceased spouse (partner).

- Taking family leave from work to care for your spouse (partner) or a spouse's (partner's) child during an illness.

-Taking leave from work if your spouse (partner) or one of your spouse's (partner's) close relatives dies.

- The right to visit your spouse (partner) in the hospital.

-Making medical decisions for your spouse (partner) if he or she becomes unable to express wishes for treatment. Making burial or other final arrangements.

-Filing for step-parent adoption of a spouse's (partner's) children.

-Right for the couple to jointly adopt children.

-Protection under existing divorce laws regarding the equitable division of property, spousal or child support, child custody, and child visitation. 